\title{
Ethical by Design
}

Managing and Measuring Digital Ethics in the Enterprise

Charles Radclyffe and Richard Nodell, January 2020

\section{ABSTRACT}

Since the Cambridge Analytica/ Facebook scandal the question of how to manage Ethics in the context of Digital technologies has risen in prominence from afterthought, to keynote agenda item. The problem is not simply that Ethics as a domain of governance is not well understood by the technology industry, but that it is either restricted in mainstream dialogue to a discussion of risk and safety issues, or it is conflated with regulatory compliance. The terms used to for structures to manage ethics, such as 'Ethics Boards' and 'Ethics Councils' are also used interchangeably. What this paper proposes is to define Digital Ethics in terms where it becomes clear that it is necessarily a separate topic of governance to regulatory compliance and technical risk/ safety management. This paper also suggests some defining characteristics of Ethics Boards and Councils and proposes alternative models. Finally, a case is made for how the quality of ethics governance can be measured and therefore managed, in order to build comparisons between organisations in language that will be familiar to investors and consumers. It is believed that in doing so, the difficulty of talking of this subject in purely subjective terms can be avoided.

\section{INTRODUCTION}

The world's attention has been caught by a spate of highprofile ethical breaches involving the world's leading technology companies. This has raised questions and begun a debate about big issues such as what limits ought to be placed on the application of surveillance technology, when might military use of autonomous weapon systems be acceptable, and whether we should develop technology that enhances human capabilities? These are all ethical questions and need to be addressed in a particular way. While it is perhaps obvious that these 'big' questions have far-reaching societal impact, in fact every organisation that is seeking to leverage technology faces ethical challenges, whether they recognise it or not. Chatbot customer service agents are given human names and gender. Emails are sent by co-workers at unsociable hours, exacerbating the anxiety of screen-time addiction. Data is being collected with the intention of being used one way, and then subsequently used another. There is a growing sense of a backlash against unbridled technological advancement; a so-called 'techlash'.

Many organisations have recognised the need to invest in structures that will help them address a loss of trust. It is not the absence of 'ethics' in relation to technology that is the problem, but the fact that many of the approaches taken to managing ethical issues generally fail. They do so in one of two ways. They conflate issues or they relegate ethical questions to a separable category of things to be thought of on their own, unrelated to the practical issues of technological development and design. Even the general level of understanding of what ethics are in the context of high-technology is limited. Basic foundations, such as a common set of reference terms are absent within the practitioner's vernacular. In those arenas where Digital Ethics is considered, it is often indistinguishable from regulatory compliance or risk and safety management. This paper aims to offer the reader a set of lenses to see the various domains separately, and a toolkit to differentiate strategies for handling them.
Next, leaders need to distinguish between various models for managing the ethics conversation within their organisation. Once again, we see evidence of terms being used interchangeably and so we offer a simple method to consider the parameters which an organisation might find helpful to assess options against. In addition to this model, organisations need a roadmap to evolve and track their own maturity in their ability to identify and then engage thorny ethical issues as they arise. Consequently, an assessment tool is also provided. Such an assessment matrix could be used by the investment industry in ways that mirror similar initiatives focused on environmental and sustainability goals. If we do not act now on the signs given by the various 'canaries-in-the-mine' - we risk building discontent and fostering further distrust. The United States has already seen one domestic terrorist motivated by a loathing of technology, and while this is as an extreme example, there are many more near-term imperatives to managing Digital Ethics in a disciplined manner.

The modern enterprise operates in times of complexity. We look back at the era before us and see strata of certainty, certainty that we seek in our own time but seldom find. The only certainty we see is that which lies immediately before us, the opportunity as best presented to us by the market and with the evidence of unbridled success and enthusiasm all about, our impulse to seek 'progress' seems validated.

Yet we are also aware of a dark side. The exploitation of technology in order to achieve commercial objectives is clearly a short-term pursuit, but the longer-term considerations and constraints are hazy if they are even at all visible. We act on impulse, aware of potential misgivings, but are blind to their consequence. History shows how this might play out and offers us case studies to help us define alternative paths. For example, the past few centuries have seen exploitation of carbon-fuel in pursuit of greater mechanisation and industrialisation. This has led to instability in our planet's climate and we are told by many experts that time might be running out to redress the 
balance. Despite the misgivings of some commentators ${ }^{1}$, it is a fitting analogy for our current age to say that we are in the midst of a new great Industrial Revolution ${ }^{2}$. Some herald this new era with excitement, others argue that it is the inevitable achievement of humankind ${ }^{3}$. At the start of this new era, it is data that takes place of the oil of old, and artificial intelligence techniques that are our substitute for petroleum refinement methodologies from a century ago.

Ethics is concerned with the management of these competing tensions. The consideration of ethics is an ancient activity, but an unsatisfying one to many. Ancient in that ethics has always been about that primitive quest for how to life a good life; one that makes life worthwhile. It is also unsatisfying because despite its antiquity, we appear to be no further forward in our resolution of these challenges. Any attempt to summarise all the thinking that has come before or to synthesise various different traditions that stem from the people around the world would be significantly misguided in its pursuit, and dangerous in its application. Given the global nature of the firms we run, and the markets in which we operate; what hope do we have of integrating notions of ethics into the high-technology that we embrace?

What is needed is an introduction to the topic for the layperson, first to orientate the reader around an understanding of what ethics is, and then to offer some practical guidance as to how to manage it in the context of enterprise technology.

This paper aims to serve this purpose. We begin with a tour of the various concepts the reader is likely to come into contact with, and an attempt to distinguish what ethics is from other important topics of consideration. Next, we expand on various models that firms have used to manage the topic. Additionally, we offer a conceptual model by which these models can be understood as distinct and separate in order to help the reader pick a starting point from where to begin. Finally, we offer some criteria to serve as guiderails for an organisation in contemplation of these issues as well as a reference standard against which to assess itself. We see an opportunity for every organisation to run an assessment of their current level of maturity against these measures. We believe that in doing so, a natural evolutionary roadmap will emerge. In addition to all this, there is an opportunity for the investor community to engage with Digital Ethics much in the way questions of Environmental and Societal Governance (ESG) are now addressed. Without seeking to be too prescriptive, we believe the maturation assessment model below can be used and adapted by organisations interested in exploring the notion of Digital Ethics ratings which we believe are likely to emerge as a priority for consumers and investors in the not-too-distant future.

\section{SECTION I: THE DIGITAL ETHICS IMPERATIVE}

While the consideration of ethics is very much an ancient affair, it is wrong to view its application to the pursuit of high technology as an anachronism. Indeed, it may be thought that the five thousand years or so of philosophical study until now has operated without an imperative to galvanise its application.

Before turning to why the digital age has created this urgent need for ethics, first we turn to two other fields where boundary conditions were not considered until the apogee of achievement, and in both cases- too late.

\section{The Environmental Sustainability Movement}

The poet William Blake recognised that the era in which he lived represented a phase-shift in the relationship between humanity and its natural surroundings. The "dark Satanic Mills" referenced in his great work the Prophetic Books ${ }^{4}$ was as much a commentary on economic changes in his home of London as much as any spiritual allegory contrasting an image of heaven on earth to the realities of early industrial England. However, in our age of environmental anxiety we typically conjure an image of tall chimney stacks belching noxious smoke into the blue sky when invoking Blake's poetry.

We cannot know the extent of any dialogue on the potential sustainability or otherwise of industrial activity at the time of Blake, but certainly as the $19^{\text {th }}$ Century progressed and the pollution, sewerage, and other phenomena such as smog made cities like London almost unbearable places to live, concerns begun to be raised as to the sustainability of industry. ${ }^{5}$

It is hard to conceive that consideration might have been given in $19^{\text {th }}$ Century Britain as to the natural limits of an expansion of industry. If one were to take the pessimistic view, then one might hold that any efforts we might make today are futile in restoring a balance to our environment. In which case, at some point in the coming decades our worldly habitat might become untenable. Those taking such a view would therefore strongly wish that earlier attention to natural limits might have been made, or indeed even pursued with vigour.

Progressing further along this line of enquiry, one could imagine that such conscientious industrialists might have weighed humanity's long-term survival at a higher precedence to their own personal short-term financial gain. Doing so would have necessitated placing limits on, say the growth of the carbon-fuel industry until such times as its effects could be understood, mitigated, or alternatives found. In this hypothetical history, one might imagine that the large-scale refinement of oil at the start of the $20^{\text {th }}$

\footnotetext{
${ }_{1}^{1}$ https://calumchace.wordpress.com/2016/11/13/its-not-the-fourth-industrial-revolution/ 
Century would be perceived as a step too far along a path towards inevitable environmental destruction. Had this been the case then the development of technologies such as the internal combustion engine might have been arrested in the interests of the planet.

Of course, we know that such deliberations were not made during the height of European industrialisation, or at least to the extent that they were, they were muted. Thus they had little effect on the enormous momentum that carried technological progress to where we stand today. We are faced with ostensibly the same choices as our industrial forebears, however, we continue to avoid taking those steps which might prove critical to our long-term survival. This is despite the fact that the cumulative effects of our activities is more immediate to us than to our ancestors.

Projecting this line of thought further, one might imagine a responsible species, a species with a collective conscious and conscientious appreciation of its custodianship of this planet, would take a long-term view of technological progress. It might consider a moratorium of a few generations or even tens of generations a worthy sacrifice to make in the interests of enduring survival.

We are alas not as responsible a species as we might wish, and now even when faced with an existential threat - our collective response remains moribund. It has not been however, for want of trying - there have been many voices over the years calling for action. What follows is the story of how the environmental response has developed - and is helpful in demonstrating the dangers of not heeding the early warning signs of potential societal problems.

The environmental movement can be categorised by two distinct phases. That of non-violent protest as characterised by organisations such as Greenpeace and a second, and more active civil unrest incited by groups such as the Extinction Rebellion. A third form of protest, a violent response - has not yet been developed; although one could foresee it to be the inevitable evolution along this trend.

Greenpeace as an organisation was originally born out of concern for the environmental impact of nuclear warhead testing. The Don't Make a Wave Committee ${ }^{6}$ was created in response to the fear that unstable land in Alaska, where the US Navy were conducting underground nuclear weapon tests, might give way and cause tsunami down the Pacific Coast of North America. This protest movement grew and attracted into orbit a number of other groups before finally coalescing into the campaigning organisation for environmental problems and their potential solutions that we recognise today.

While written-off by many, particularly in the first few decades of its existence, Greenpeace has become one of the most widely recognised bodies campaigning for sustainability. Throughout the timespan of its activities, many organisations, particularly in the oil and gas industry have seen Greenpeace as an irritant and an entity which seeks to frustrate their commercial goals. Yet, to others; Greenpeace is seen as a champion of the natural ecosystem, and through the awareness it has created, has done much to improve the condition of the environment and contributed to limits being placed on the risk of longterm harm.

It is despite these achievements, and the slow trend of greater conscientiousness on the part of citizens across the world that the pace of change has not been great enough for some. Particularly the generation born since the millennium are taken to more extreme methods to have their voices heard. The lesson to be learned here is to heed the warning cries, there is always a more active protest movement waiting to be given an excuse to take root.

The mainstream popularity of civil disobedience as a strategy to encourage more radical actions to limit climate change such as the cessation of air-travel or the avoidance of meat-eating, can be traced back to August 2018 where Greta Thunberg protested outside the Swedish parliament in Stockholm in place of attending school. Her sign, "School strike for climate", inspired other young people across Sweden and beyond to not attend school and spend the time instead protesting for change.

Two months later, in October 2018, a protest in London was convened inspired by the Occupy movement from the start of the decade. Using similar methods of civil disobedience and occupation of public spaces with resistance against law enforcement, the Extinction Rebellion achieved notoriety as a highly focussed interest group willing to seek widespread disruption to society in pursuit of raising awareness for its aims.

At the time of writing, it is not known whether this trajectory of increasing agitation from ordinary citizens will succeed in its aims of limiting the most destructive effects of industrialisation, or indeed whether more ambitious and more disruptive organisations will in time appear. What is clear though is that a pent-up frustration unaddressed by business and politics has led to activists willing to take matters into their own hands with less respect for traditional and purely democratic methods of dialogue.

The theme presented here is punctuated by a progression of key steps:

- Exploitation of a previously undiscovered method or resource in order to achieve commercial ends;

- Unintended consequences being observed in localised instances;

${ }^{6}$ The Greenpeace Story, Michael Harold Brown (1991) 
- Acceleration of investment and development as the feedback loop solidifies around the commercial goal, despite increasing evidence of long-term risks;

- Widespread recognition of at least the potential for long-term harm, but limited intervention;

- Regulatory intervention trailing civil activism.

While Greenpeace was ahead of the curve in their identification of the risks and proposed solutions, many only started to recognise the severity of the problem after catastrophic findings such as the 1985 discovery of the hole in the ozone layer ${ }^{7}$. How much better would the situation had been had the early warnings been taken more seriously - perhaps some of the worst effects of environmental damage (likely to be those yet to come) - could have been averted.

\section{Greed isn't Good: The Financial Conduct Clean-up}

The steps illustrated above are similar to those that led to the Global Financial Crisis of 2007-2008. The aftermath of the economic downturn led to a lasting period of reputational damage for the Financial Services industry. The causes of the crisis are multitude and shrouded in controversy. However, most people would be tend to agree that it was caused by a combination of regulation failing to protect the most vulnerable in society from being exploited, in parallel with the market prioritisation of profit (short-term goals) over societal benefit (long-term goals).

Since 2008 , there has been a sea-change in attitude within the Financial Services industry. Most notably, there is today a cultural expectation within this industry that everyone is a risk manager - regardless of their job title. Pre-crisis, the prevailing view was that risk and compliance teams were there to 'mop up the damage' when things went wrong. Today, it's widely recognised that everyone has a responsibility to ensure customers are treated fairly. To be sure, there is still more work to be done, but those who work in this sector and who are users of its services can be confident that the worst of the excesses lie behind.

Many commentators ${ }^{8}$ have acknowledged that over the last few decades commercial power and influence has shifted West from Wall Street to Silicon Valley. The cultures of these two epicentres are in many ways diametrically opposed. Wall Street has a long reputation for being a cutthroat centre of financial power, epitomised by the 'greed is good' mantra of its eponymous movie. Silicon Valley, on the other hand, has a reputation for libertarian culture where technology can be developed in an environment of freedom, and utopian ideals for how the world might oneday look can be experimented with.

To some, the excesses of Wall Street compared to the egalitarian nature of the Valley appear as two systems in contrast with each other. One inherently good and desirable, the other bad and unsustainable. Yet this is a superficial characterisation. More significantly, it does not acknowledge that any unidimensional system is inherently dangerous.

Only recently have the weaknesses in the Silicon Valley approach been brought to the fore. The power of consumerisation has led to the ubiquity of devices and software in each of our palms and on our desktops. These, along with the incredible volume of data ${ }^{9}$ that the Tech Titans collect on us, have given these organisations unprecedented power and influence ${ }^{10}$, not least to mention the capital value also created in the process. ${ }^{11}$ With incredible power comes incredible responsibility, and individual examples of failure such as the Cornell/ Facebook 'emotional contagion' controversy ${ }^{12}$, or scandals such as the worker conditions of Amazon employees ${ }^{13}$ have raised awareness for a previously unrecognised field of concern, a field we call Digital Ethics.

While we don't seek to make the case that there is a direct parallel between the effects of the digital technology industry and the effects of industrialisation, what concerns us is that if left unchecked, isolated cases of abuse or unexpected side-effects might cause pockets of protest and widespread revulsion. The Luddites of early $19^{\text {th }}$ Century England cannot be written-off entirely from reappearing in the history we are writing today. After all, the 'dark Satanic Mill' in Blake's poem, the Albion Flour Mills of Bankside, London was destroyed by fire, likely arson, and its reduction to ash was celebrated by the local independent miller community. In the last century, the 'Unabomber', Theodore Kaczynski compiled an essay ${ }^{14}$ calling for the detechnification of society at the same time as sending mailbombs to the victims he felt best personified his concerns. ${ }^{15}$

We are today operating in the equivalent times to the refinement of oil stage of the industrial revolution. Digital technology is already ubiquitous, as was steam-power and machinery during the height of coal-powered industrialisation. What we observe today are the first effects of technology in changing society and we have to balance our short-term commercial goals against the need to consider our long-term endurance if we are to stave off the coming backlash against technology, or 'techlash' as coined by The Economist ${ }^{16}$ in 2018.

\footnotetext{
${ }^{7}$ https://www.nature.com/articles/d41586-019-02837-5

${ }^{8} \mathrm{https}: / /$ www.theguardian.com/commentisfree/2015/apr/19/wall-street-courting-silicon-valleynew-shift-in-power

${ }^{9}$ Big Data, Kenneth Cukier and Viktor Mayer-Schönberger (2013)

${ }^{10}$ The Age of Surveillance Capitalism, Shoshana Zuboff (2019)

${ }^{11}$ The Winner Take All Society, Philip Cook and Robert Frank (1995)
}

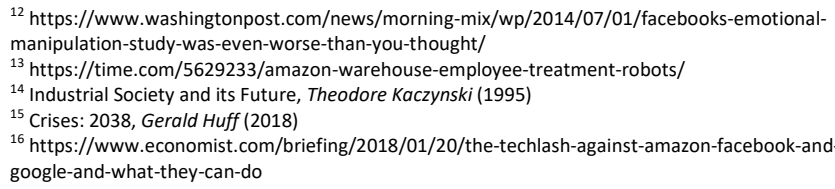

${ }^{12}$ https://www.washingtonpost.com/news/morning-mix/wp/2014/07/01/facebooks-emotionalmanipulation-study-was-even-worse-than-you-thought/

${ }^{13} \mathrm{https} / / /$ time.com/5629233/amazon-warehouse-employee-treatment-robots/

${ }^{14}$ Industrial Society and its Future, Theodore Kaczynski (1995)

${ }^{15}$ Crises: 2038, Gerald Huff (2018)

${ }^{16}$ https://www.economist.com/briefing/2018/01/20/the-techlash-against-amazon-facebook-andgoogle-and-what-they-can-do 
A world where industrialists had considered the environmental, political, and social impacts of their creations might have been a world with less war, diminished revolution, and greater equality. This would have come at the cost of 'progress' at least according to a very narrow definition of the term. ${ }^{17}$ However, what if we were to consider that it might have actually led to an increase in the ingenuity of innovation, for there would have been greater impetus to invest in methods and technologies that achieved the outcomes sought after, perhaps with the harmful effects mitigated or minimised.

There is one final point on the urgent imperative for Digital Ethics. The global financial crisis led to investors considering the long-term stability of their investment funds, paying attention to corporations with weaker riskmanagement and those with more 'commercially-minded' attitudes towards regulatory compliance. This, in turn, led to financial instruments being priced accordingly. So too, have we seen consumers investing with their wallets in financial firms they trust ${ }^{18}$, where they feel less exploited or more in partnership with the firm who helps them manage their finances.

There is a direct parallel between this and the current investor and consumer attitude towards environmental sustainability. A small number of consumers began to pay above market price for goods labelled as 'Fair Trade' in the belief that purchasing these products not only aligned better with their value sets but also had the effect of furthering their impact goals. As the number of these consumers have grown, so have we seen a growth in the number of investors also recognising either a desire to invest in opportunities with a strong sustainability component, or indeed recognising the long-term financial benefits for doing so.

We believe that the same trend will emerge in relation to Digital Ethics. We are currently in the phase where a small number of consumers are 'voting' with the currency of the internet: their attention. As the techlash grows stronger, the need for a Digital Ethics rating system for firms to support the investor community will surely only grow in importance.

\section{SECTION II: DEFINING ETHICS}

We are born into a world where resources are finite and asymmetrically distributed. Our own abilities are multitude and unevenly spread. While this diversity gives rise to strength in terms of the enduring nature of our species, it creates a requirement for the regulation of affairs between us.

There are many methods that we are familiar with which aspire to bring principles of ethics to this regulation:

\section{Law}

Some of these methods are prescriptive such as that encoded within the various laws and cases determined by our legal system.

These evolve as does public awareness of the change occurring: environmental and civic events, new economic, social and political forces as well as innovations in technology. Collective awareness develops conversational modes to review the impact of the change, what to do about it, and how to anticipate further transformation. At this point people develop plans to adapt to evolving change by creating systems of governance.

Governance evolves through a combination of determining parameters and responses for and to events yet to unfold, as well as the retrospective adjudication of events that have already transpired.

Such systems have the effect of bringing commercial certainty to the enforcement of transactions between parties. Moreover, they enable societal acts of justice in answer to those aggrieved. The rule of law has the benefit of creating a level-playing field to actors within a system. While a strong sense of consistency might be discovered through general principles that surface over the course of time, law is only ever at best an external fiction to which we agree to subject ourselves ${ }^{19}$. This offers the individual no recognition of the internal desires and interests that exist in each of us.

\section{Ritual}

Nor is the study purely of behaviour satisfactory in helping offer guidance as to an equitable method to follow. Rituals tend to be more grounded within cultural or community norms and like legal rules; they are an external measure that facilitates some collective activity. Rituals lie at the intersection of normative and personal approaches to regulate affairs.

With matters that emerge as something new and unexpected; and as novelties and anomalies arise, the

\footnotetext{
${ }^{18} \mathrm{https}$ ://uk.reuters.com/article/uk-britain-banks/british-public-dont-trust-banks-10-years-aftercrisis-survey-finds-idUKKBN1L11EL

${ }^{19}$ Robot Rules: Regulating Artificial Intelligence, Jacob Turner (2018)
} 
original intention of all ritual and ceremony becomes attenuated. When the world changes too much or too quickly, ritual acts lose their meaning and their power as social bond. Individuals feel more and more dissociated from these rituals as they fail to mirror their ever more complex inner lives. They fail to provide direction of how to behave when new situations arise.

They might yet still offer allegorical reference to a system of fairness that their practitioners seek, but as a universal and enduring system - they inevitably fall short.

\section{Morality}

As society evolved, this tension between inner life and social life, between what one was told to do and what one felt was right or wrong to do, gave rise to philosophy. To study and direct thinking about right and wrong, is what we call moral philosophy.

Assessments of morality recognise the need to balance values and outcomes. They tend to appreciate that external forces and factors mould our lives. They change the moral assessment of any given action as it moves from one context to another. For our purposes however, morality is a private affair and seeks only to offer comfort to the individual in contemplation. This may at times provide instructive guidance but, more often than not, merely comfort and solace from the act of sense-making they bring to their behaviour.

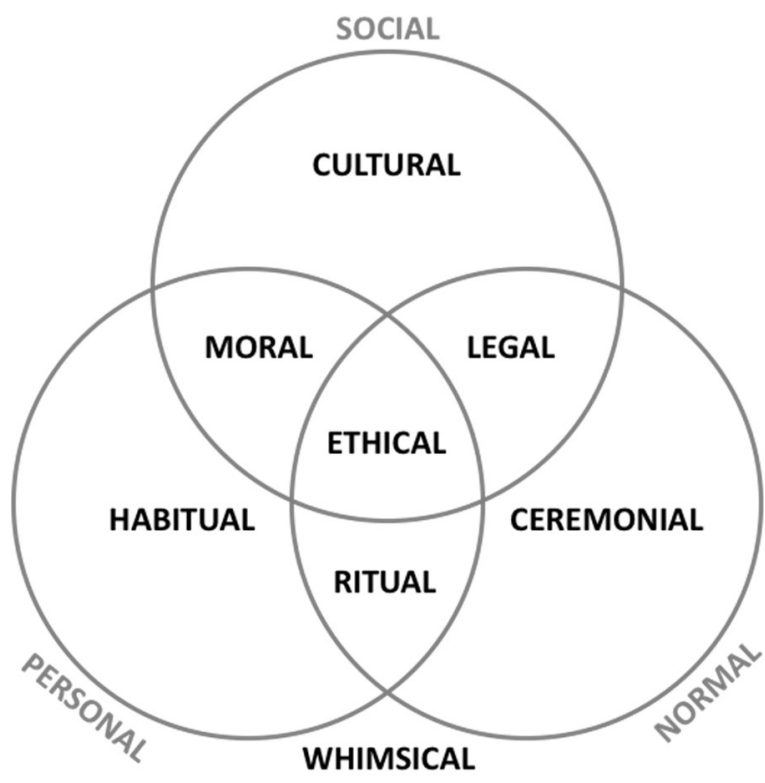

Figure 1: A representation of ethics in contrast to other expressions of regulating behaviour.

\section{Ethics: balance of normative, social and personal forces}

What is missing from each of these fields of inquiry is first a systemic understanding of how norms of human behaviour arise in the interaction between social conventions and individual adaptations. These norms regulate the way transactions take place. They establish the value by which behaviour and objects are assessed. These establish the range of what is considered good or bad, right or wrong. They can be codified as principles and vary from one society to the next. For each society this set of norms and principles constitutes its ethics. Consequently ethics are to be understood as the grammatical structure of values for any given society. These values determine the measure by which one lives well with oneself and in accord with others.

While morals are private reflections on sociable behaviour, rituals contrived through normative development, and laws imposed from the apparatus of society; a study of ethical activity seeks to recognise that we only ever exist in relation to each other and a discovery of ethics therefore can only be made through dialogue and conversation.

\section{Whimsy}

It is at this point that specific reference ought to be given to capricious activity that stands in contrast with ethical behaviour. Such whimsy can often be thought of as humorous or idiosyncratic, but only when directed at oneself or within safe social constraints such as in the absence of power. Capricious activity that lacks any selfreferential integrity, from a position of power or strength only serves to increase entropy. This is contrary to the order that we crave. In short, whimsy is the antithesis of what we seek in a discovery of principles of good ethical design.

Whimsy and arbitrariness in the context of the contemplation or use of power is seldom purely capricious however and is more likely to be found as representing an underlying structure or system of belief. Indeed, a moral compass will at least have a self-orientated or gratifying direction and thus lack the character of whimsy even if it cannot be readily explained or understood by others.

\section{Aesthetics}

Similarly, there are systems of consistency that don't profess to make judgement as to the inherent rightness or wrongness of an activity but speak to a preference of the individual or group subscribing to such a position. An example of this would be a stylistic conformity. The fact that this whitepaper has been written in a typeface that is sans serif as opposed to a font with character adornments is an example of an aesthetic choice.

Aesthetics and ethics can be easily confused. Both appear to be systems where there is a self-referential integrity to their organisation around a principle or set of principles. 
Aesthetics are often, however, more technical in nature, and in being so are derived in relation to objects rather than in relation to another. They might also simply reduce to a matter of taste, taste of an individual, of a subculture, a corporate entity, or even an era. At the core they represent an organic (even if self-aware) network of preferences. ${ }^{20}$ They are based on what we like and what we don't. We can be proactive in our tastes but the original experience is passive and reactive.

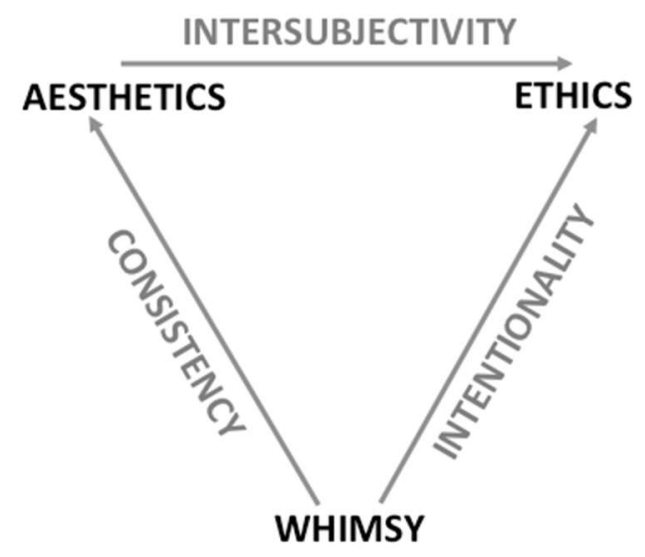

Figure 2: A diagram showing the relation between Ethics and other fields.

\section{Ethics: the field of intentional intersubjectivity}

Ethics is a distinct activity, the field where both principles of intentionality and intersubjectivity are strong and tend to be indifferent as to any inherent consistency, however hard such a schema might be sought or desired. It must be understood not as a subject matter, but as an endeavour. Ethics is therefore like cooking, and not cuisine; like playing, and not sport; like singing, and not music.

Ethics therefore are the realm of inquiry and action that arises in the relationship between one and another. The discovery and establishment of the principles that emerge can only be negotiated from within a given particular relationship. Ethics cannot be imposed on it. It therefore does not help to speak of a 'code of ethics', unless one is documenting principles that exist and have been communicated between groups or individuals. If a new party joins the group, and their own relation to the 'code' has not been ascertained then the code loses its magic and becomes merely an aesthetic. (Of course, the code might very well be intended as an agreement of norms born out of an assessment of values between parties standing in opposition to another. In which case, the 'code' might well still be 'ethical' in nature even if it is not accepted universally in a positive light.)

To follow this line of logic, whereas in the vernacular we talk of the Hippocratic Oath ${ }^{21}$ as being a 'code of ethics' it is in fact no such thing. It is a principle that has generated a normative structure imposed on medical practitioners and cannot hope to speak to the various considerations a doctor might face in her line of work. Similarly, The Ten Commandments ${ }^{22}$ offer no insight into the intersubjective agreements between the Israelites accepting, as we do, their communication from the Hebrew God to Moses. They ostensibly received them as law. As they were discussed and argued about through exegetical study and structured dialogue, over generations they became used of as a code of ethics as opposed to an aesthetic one.

It is clear therefore that such a definition of ethics stems from relationship between parties and can only be ascertained through dialogue with the affected parties. It is the intention to put a value or basket of values in advance of others such as to address or redress an imbalance in the state of relations between the parties. A common mistake is to look for agreement on things which are inherently good and ascribe these statements as 'ethical'. This is a category mistake. Whether something is ethical is the degree to which consideration has been given to the impact of the thing on the balance of relations that exist between parties. If no such consideration has been made, then the matter is in the realm of aesthetic. If no intentionality was conceived then the matter is purely whimsical.

Ethics always stand as an activity that considers the distinct relationship between parties and is neutral to any desire for consistency. Where an activity is unintentional, then it is no longer something which can be said to be 'ethical' and instead resides in the realm of whimsy.

\section{Ethics: an activity that is neutral on outcomes}

An example might serve to illustrate this point. The painting of one's house according to an individual preference can be considered as a whimsical idea. However, if the house is situated in a wooded area, and the colour serves to be more sympathetic to the surroundings then the decorative act can be said to conform to a particular aesthetic. Expanding on this, the homeowner might decide to add patterns to the paintwork. These patterns might be random, or align to no system that can be articulated, and thus again becomes whimsical. There might be a desire though for geometric order in which case this activity once again becomes an act of aesthetic preference. However, imagine the instance where the embellishment is a cross with directional tips at each of its arms such as in the case of a swastika - in this case then, very much an ethical choice has been made. It does not matter whether the intent of the image is for peace and good fortune such as the original meaning of this symbol ${ }^{23}$, or as a symbol of hatred - in either case the effect is one of changing the relationship between people or groups and therefore its addition can be said to be an act in the ethical domain.

\footnotetext{
${ }^{20}$ Complexity and the Nexus of Leadership, Jeffrey Goldstein (2010)

${ }^{21}$ The Hippocratic Oath and the Ethics of Medicine, Steven Miles (2005)
}

${ }^{22}$ Exodus 20:2-17 and Deuteronomy 5:1-22
${ }^{23}$ The Swastika: Symbol Beyond Redemption?, Steven Heller (2008) 


\section{Ethics: human activity}

Another example of such confusion is to ascribe 'ethicalness' to technology or machines. All humans have a conscience, the term we use to process the difference between right and wrong. (All humans, that is, except for those we label as psychopaths, for they somehow lack empathy and while might well have developed the ability to fake the appearance of a conscience - such an appearance is illusory, a mask to help them better assimilate into society).

Of course, those of us in the non-psychopathic population vary greatly in terms of our behaviours. Poets, priests, and politicians mix freely with child molesters, misogynists and murderers. We are all 'ethical' beings, in that we all have the ability to process right from wrong, yet there is a varied spectrum of behaviour that exists across us all. To say that someone is 'unethical' is a misnomer, what we mean when we say this is that we assess their behaviour as being contrary to our personal ethical judgements which, in turn, are derived from a social norm. These norms vary with context. Someone who has committed murder might have done so in self-defence, and therefore both ethically and in law could be innocent of any charges brought against them. We reassess the ethics according to the situation, our own context as well as our relationship with the others who we conduct this activity with.

Machines might well be programmed to act in such a way as to give weighting to a particular outcome over another. ${ }^{24}$ A machine might take a utilitarian stance and seek to maximise utility either to the largest group or in aggregate across the entire group. Even utilitarianism presents at least two choices to the robot - but is the choice of either an ethical choice? As machines cannot empathise with humans, and cannot develop an intersubjective dialogue with us, they cannot ever be said to be ethical. To call them so is dangerously misleading, for the vernacular use of the word implies a 'goodness' of intent, where clearly none can exist. We maintain that the machine can be designed according to ethical principles, but this cannot speak at all to the actions of the machine. Doing so is a category mistake, but one which sadly is too often made.

\section{Ethics: a practical endeavour not a thought-experiment}

Finally, turning to perhaps the best known 'ethical' test for machines - the so-called 'trolley problem'. The Trolley Problem is often cited as an example of the difficulty of programming machines to distinguish between outcomes ${ }^{25}$.
There have been many variations of the problem over the past century, but the most widely recognised form was that introduced by Philippa Foot in 1967:

\section{You see a runaway trolley moving toward five people tied up on a track.}

2. You are standing next to a lever that controls a switch.

3. If you pull the lever, the trolley will be redirected onto a side track, and the five people on the main track will be saved.

\section{However, there is a single person lying on the side track.}

\section{What do you do?}

While a useful thought-experiment to highlight the differences between two schools of moral thought, namely utilitarianism and deontology - applying it to the design choices in autonomous vehicle creation is a mistake.

As a thought-experiment, we can choose between the two options in front of us, and variations of the problem might cause us to change our answer (e.g. what if the single person was a child, and the five people elderly? What if the five people were relatives, and the child that of a stranger?). In the luxury of our own mental conception of this problem we are free to choose between options, but out in the field it is a different story. None of us can know with any certainty whether we would act or freeze, and what premeditation there might be for our action. As instinctual beings, what we do is to post-rationalise our behaviour in order to seek to conformity with some model or morality. Machines have no such ability to shirk the premeditation of their action.

To help us solve real-world trolley problems, we have developed an elaborate system of law which first seeks to 'discover' the facts of the situation and then secondly looks to legality of the behaviour. The 'discovery' of facts is a legal fiction. While those indicted profess their postrationalised version of the truth, we know that this is arbitrary. We turn to witnesses and look for other clues in order to assess the veracity of their statements. Once the true sequence of events has been decided, we then judge the legality of their behaviour. Our laws give us either a prescription of what to do in these circumstances or might afford the judge some discretion to create new law to apply to the facts. Regardless of the legal system the result is a first level of response. In cases where an injustice is perceived to have occurred, the news media can subsequently encourage the public to consider alternative views (and often lead them towards a particular position). This is the second level of response, the 'Court of Public Opinion'26. Thirdly, and finally, the legislature might act to

\footnotetext{
${ }^{24}$ http://eprints.uwe.ac.uk/24467/1/Winfield_Chapter_in_ComputerAfterMe_finaldraft.pdf

${ }^{25}$ Would You Kill the Fat Man?, David Edmonds (2015)
} 
redress any deficiencies in the process, and in the case where the accused has been convicted unfairly - they might see their sentence commuted or pardoned.

If we are to solve real-world problems such as this, we need to repurpose our existing apparatus for adjudicating between outcomes rather than encode empirical research from thought-experiments in machines. The first is very much an ethics conversation to be had, the latter merely a category mistake.

A way of making minor adjustments to our existing apparatus would be for a regulator to compel autonomous vehicle manufacturers to fund 'mock' trials of hypothetical events in order to test out the issues at stake. A manufacturer might be compelled to have brought all factual circumstances for which it sees a likelihood of occurrence in the real world and using the existing judicial system and the transparency of media reporting to test out these 'cases'. Aside from some minor regulation, the only tweak to our existing system would be to allow for 'mock' trials to take place alongside the Court system. For an industry that prides itself in tradition and heritage, this might however be an innovative step too far.

Of course, to say that ethics is neutral on a scale of positive impact is an unsatisfactory position for most people tasked with the design or implementation of technology. What is therefore necessary is to adhere to a framework or process that serves as guiderails that are more likely to promote positive or equitable outcomes. It is this subject that is the scope of this whitepaper. Positive or equitable outcomes are indeed the intended consequence for those who accept our approach. With the methodology that is offered in the pages that follow, people and organisations can focus their efforts at activity that is more likely to lead towards desirable outcomes. In doing so they de-risk the actual harm and reputational damage that comes from mistaking or ignoring questions of ethics. An additional benefit of this is to exert a gravitational pull on talent, customers, and capital that prefer consensually agreed upon outcomes over those which are capricious or inequitable.

\section{SECTION III: DOMAINS OF ETHICS}

Returning to the relationship of ethics concerns to those of a legal, ritual, or moral nature - it is important to make one further distinction: the subject of ethics stands as a separate activity to the subject of regulatory compliance or to worries that relate to the management of risk or safety. It is also important to stress that not only are the category of concerns different, but also that how they are best managed in the enterprise ought to be seen through a different lens and spoken of in different forms of conversation.

\section{Regulatory Compliance}

Clearest perhaps is the distinction between ethics and regulatory compliance. While both are external considerations of acts and processes, as opposed to the purely internal and subjective domain of morality, they are often conflated in conversations about the management of ethics when those conversations concern societal-wide challenges. It is clear though that a relationship does exist between these two domains despite the differences in their character and effective management ${ }^{27}$. For instance, an organisation might settle on a particular principle that reflects the balance of values amongst the stakeholders they have consulted. An example of this might be a principle that chatbot or conversation agent technology adheres to gender-neutrality. Another organisation might also consider gender-neutrality of their chatbots, but decide it is against their commercial interests ${ }^{28}$ because research into this has found that chatbots which identify with a particular gender tend to achieve higher useradoption $^{29}$.

Each of these positions are ethical determinations although they are clearly different. It also happens to be the case that both these positions might be reached through use of the methodology proposed in this paper. No judgement is offered or intended as to the rightness or wrongness of any particular outcome. It is hoped that in such scenarios that a 'marketplace' for ethics would emerge. The use of the term marketplace here is meant as that the ethics principles of various organisations are transparently represented to consumers, so that a choice can be made as to whether a customer cares sufficiently to align their shopping behaviour or investment decisions with their values. Some firms would balance their values one way, while others would take a different view. Each could score equally highly according to the proposed rating system below. What would likely transpire though, is that a regulatory body might decide to step in and mandate a particular position in order to level the marketplace or achieve some other public interest outcome. If the use or application of such a technology can be considered in a broader context than a niche or industry then perhaps guidance or compulsion is

\footnotetext{
${ }_{28}^{27}$ http://www.cs.bath.ac.uk/ jjb/ftp/Bryson19AlforLawofAl.pdf 
enacted through legislative process - in either case, the issue has moved from one of ethics to one of law.

The management of regulatory compliance is a welldeveloped field. Firms contract or employ experts in the subject matter to advise as to the impact of internal processes and to devise policy to stay within the right side of the law. They might go further and engage in public policy discussions in order to influence the enactment or refinement of regulation. In either case, these activities are characterised by the deployment of expertise and knowledge to ensure the aims are met. This paper contends however, that ethics is an intersubjective domain and ought therefore to be handled in a way appropriate to interpersonal process as opposed to it being an expert driven process. Later, various models of managing ethics will be considered - but firms that choose purely to outsource the pursuit of ethics to experts create an unnecessarily difficult task for themselves. As ethics is inherently an intersubjective activity, its discovery and effective management is better achieved through structured and collaborative conversation rather than contemplation. It is argued that methods that seek to widen conversation in organisations and their constituent stakeholder groups are likely with less effort to be more successful at managing ethics than those who take an expert-led approach.

\section{Risk/ Safety}

Like with regulatory compliance, the subject of risk and safety management is a separate domain to that of ethics. Risk is the study of outcomes and the likelihood and impact of their occurrence. An actuarial rigour is required to consider the various permutations and to assess the cost of their avoidance or mitigation. Similarly, safety is a specific form of risk management which tends to consider nonquantifiable goals. Risk and safety management can be considered a well-advanced discipline, and best practice consists of organisations identifying the risks to be avoided, considering how they might arise, the likely impact and probability of their occurrence, and devising frameworks to encourage their avoidance or mitigation. This domain is dominated by mathematical assessment and engineering standards ${ }^{30}$. It is the domain of process and is the mitigant of unintended consequence. It is a critical field to ensure the survival and flourishing of our institutions.

Once again, this is a separate field to the study of ethics and can be best clarified by way of example. The Human Resources department of an organisation might decide that it can achieve a goal of lower employee attrition or reduced on-boarding costs through the use of an algorithm to classify resumés in order to prioritise the human review of those which seem to reflect success in the organisation. It is well documented that such tools can be very effective ${ }^{31}$, but also carry risks such as if the underlying data which they are trained on reflects some bias or preference for a protected category such as ethnicity or gender ${ }^{32}$. Such risks can be mitigated, and the question of "how do we prevent the resumé scanning bot becoming racist?" is exactly the category of question that a corpus of best practice has already been developed to answer. These principles or standards are not ethical standards (a category mistake), but rather risk/ safety standards and it is important to see the distinction between them. On the one hand, risk/ safety is managed best through process, frameworks, and standards whereas ethics is managed through structured conversation and guided by principles. The ethical question that relates to this example is to ask "under what conditions might it be OK to use algorithmic technology to scan resumés?". No external standard can be devised to answer this, it can only be answered through structured conversation with relevant stakeholders and through consideration of the most appropriate response based on the particular weighting of value set for that organisation.

This paper does not seek to downplay the importance of managing risk/ safety concerns in the design or implementation of technologies such as Artificial Intelligence by way of example. Ensuring principles such as fairness, transparency, explainability [sic] and mitigating bias are critical if we are to achieve societal wide acceptance of these technologies. Indeed, the diligence through which firms ensure risk/ safety questions are managed might well be a consideration by which individuals assess the ethicality of the use of such technology. However, it is again a category mistake to confuse a technical domain with an intersubjective one. Standards are things which are imposed upon people by experts, whereas genuine intersubjectivity provides for the natural give and take that occurs between people.

To some readers, the inclusion of bias as an example of an end result that is best managed through technical standards and process might appear strange in a paper arguing for recognition of intersubjectivity as a primary factor in the management of ethics. Our usage of this term in its present context is focussed on the meaning given it by the artificial intelligence community ${ }^{33}$ as opposed to any conscious or subconscious human predilection to discriminate. Going further, it is dangerous for organisations to conflate these issues without paying regard to the potential gaps they are exposing themselves to, as it is likely that in these gaps that ill-feeling and resentment will breed, and in the long-term reputational harm will occur. An organisation that has a clear separation articulated between the regulatory, risk, and ethics spheres can be confident that it has done all it can to endure from a reputational perspective. While ethics is very much a human concern, it has a very real commercial benefit.

\footnotetext{
${ }^{30} \mathrm{https} / / /$ standards.ieee.org/industry-connections/ec/autonomous-systems.html ${ }^{31} \mathrm{https} / / /$ medium.com/datadriveninvestor/7-benefits-of-an-applicant-tracking-system2c69fe5b715c
}

\footnotetext{
${ }^{32}$ https://www.reuters.com/article/us-amazon-com-jobs-automation-insight/amazon-scrapssecret-ai-recruiting-tool-that-showed-bias-against-women-idUSKCN1MK08G ${ }^{33} \mathrm{https} / / / \mathrm{hbr}$.org/2019/10/what-do-we-do-about-the-biases-in-ai
} 


\section{SECTION IV: DIGITAL ETHICS CHALLENGES}

What follows is by no means an exhaustive list but offers the reader a glimpse into the types of challenges a Chief Ethics Officer might face in a newly created function.

An insurance company has recently moved into a new office building, and as part of the commissioning of the new premises it has been reported that the automated firealarm system uses a male voice to signal an evacuation and a female voice to signal a test.

A charity which is set up to provide counselling to those at risk of suicide becomes inundated with enquiries and is considering the use of an automated chat-bot to deal with the queue of people waiting to speak to a live human. Potentially, this bot might be used to deal with 'low-risk' cases.

A property developer is concerned about potential antisocial behaviour on their estate and has installed state-ofthe-art facial recognition technology in order to help identify repeat offenders and provide their details to law enforcement agencies.

A supermarket has reached a plateau for the penetration of their loyalty card programme and is now seeking to identify un-registered shoppers based on the patterns in their transaction data.

A military organisation is concerned about the risks of sending ground troops deep into enemy territory and considers the use of autonomous weaponry which can target individuals based on characteristics such as their posture, gait, and clothing. This is a breakthrough as facial recognition is nearly useless for use by airborne drones, or against savvy individuals who have disguised their appearance.

An autonomous taxi manufacturer has perfected all aspects of vehicle control but is building human-like variances into how their cars drive so as to better blend them into traffic so other road users won't notice they are autonomous.

A bank is trialling a system that can detect the demographic profile of a customer walking past the window of a branch, and in doing so can display more targeted advertising; which, early testing indicates leads to a large uplift in branch footfall.

A law firm has installed a cognitive search tool that has led to a dramatic improvement in productivity of paralegals. They are delighted by this new technology but are concerned that future 'productivity tools' might render essential aspects of their training unnecessary and therefore leave them ill-equipped to compete in the skillsmarket against those who undertook training 'the oldfashioned way'.
A consumer electronics manufacturer creates a digital voice assistant but is concerned that users tend to unplug it at night as the green power indicator is a visual intrusion in the darkness.

An online company has designed an IQ testing app for fun, but reports have been made that the developers' real intention is to gather evidence into the correlation between $I Q$ scores and certain lifestyle choices.

A local council authority is using drone technology to conduct investigations into citizens making home improvements without the required planning consents.

A medical device company is producing prosthetics using $3 D$ printing that are almost indistinguishable from natural limbs but give the wearer significantly improved strength and dexterity.

An organisation with religious affiliations has created a bot that offers comforting words based on doctrine to users who pose questions to it. An upgraded version has proven more effective at getting users to return on a daily basis and the organisation has seen an uplift in donations as a result.

A political movement finds that its key messages can be adapted using similar approaches to autonomous email headline writing software and resulting in a dramatic improvement in recipients sharing such messages on social media.

A food processing company discovers that it can adapt an age-old recipe using feedback generated from an algorithmic system, yet it seeks to find a way to legitimise its continued connection with the cottage industry branding from which it originated.

A method has been discovered to slow the aging process by $25 \%$ but the procedure costs $\$ 10 \mathrm{~m}$ and needs repeating every decade in order to remain effective. It is hoped that in the future the same treatment could be offered for as little as $\$ 100 k$.

A hotel considers replacing front of house staff with checkin kiosks to 'improve guest experience'. The remaining reception staff are concerned that their role has become superfluous and the tasks that they are left with are demeaning.

It is important that an organisation concerned about the potential scope for Digital Ethics incursions in their own domain consider how best to source examples - while there is always likely to be a preference to crowd-sourcing the types of issues people actually care about, careful thought needs to be given to so as to avoid the risk of a Digital Ethics function becoming 'political correctness gone mad'. 


\section{SECTION V: MODELS FOR ETHICS MANAGEMENT}

If any doubt still remains in the reader as to the necessity for people and organisations to consider Digital Ethics as a component of their technology strategy, then reference is made to the 2017 publication from the Chinese State Council on New Generation of Artificial Intelligence Development Plan ${ }^{34}$. This paper outlines China's Al strategy and pays close attention to the need of balancing the compulsion to innovate and desire to achieve dominance of the Al technology industry alongside the imperative to ensure the long term "two hundred year" goals are achieved. It makes clear that China's ambition is for investors in Al to pay particular regard to the effective management of Digital Ethics as the paper is peppered with references to the subject.

Similarly, in the UK, the Centre for Data Ethics and Innovation ${ }^{35}$, is tasked by the British Government to shape policy and recommendations to industry and seek to balance innovation with governance. This whitepaper builds on these policy concerns and offers the reader a practical methodology to manage Digital Ethics in the enterprise as well as the ability to assess its progress towards a reference standard for effective management of ethics concerns as relate to the design and implementation of technology.

In the first section we have already defined the field of ethics as the explorations and negotiations that take place in intersubjective intentionality and have drawn contrasts with other related disciplines such as risk/ safety management and regulatory compliance. In this section we turn to two aspects of ethics management, the level to which a firm integrates the topic into its strategy and the level by which it distributes engagement throughout the organisation. In doing to, we consider four alternative models for ethics management which organisations can choose between.

It is worth noting at this juncture that there is certainly no consistency in usage of the terms that follow in their common handling in industry at this point in time. What is hoped is that this section will serve as a guide to the audience to consider competing tensions that are present when orientating their intended goals, and in time might encourage industry to become more precise with their employment of concepts as opposed to the current tendency for interchanging application and conflation of meaning.

\section{Distribution of Engagement}

The first axis of contrast in various organisational approaches is that by which distribution of engagement is sought widely across the enterprise or is confined within a

${ }^{34}$ https://flia.org/wp-content/uploads/2017/07/A-New-Generation-of-Artificial-IntelligenceDevelopment-Plan-1.pdf panel of experts. We characterise this as either an inclusive or exclusive approach and seek to reserve any judgement as to any preference between them.

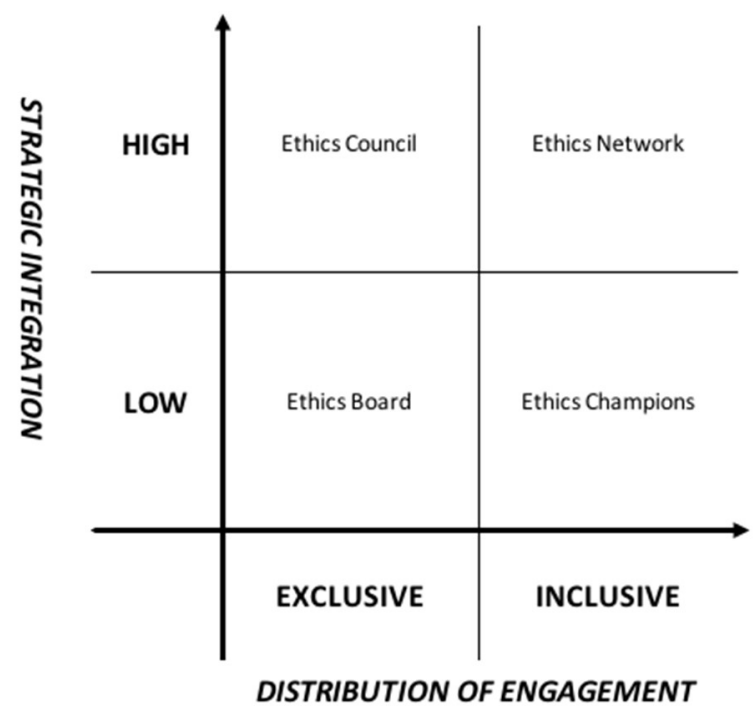

Figure 3: Comparing and contrasting various models for ethics management in the Enterprise.

Between these two centres of familial resemblance lies the tension of recognition that while ethics is inherently an intersubjective activity and one where every point of view is of equal validity, it is also a difficult and important subject. Therefore it follows that there might be a natural desire to introduce a level of expertise to the subject who can bring clarity to the thinking.

Proponents of exclusive models run the risk of limiting the field of enquiry of ethics issues to the technical challenges, and therefore are most often in danger of conflating issues of ethics from issues of risk and safety. This can be mitigated by ensuring an interdisciplinary approach to ethics management. We do not offer any prescriptive guidance on this point, other than to stress that if the desire is to ensure as full a coverage across the scope of ethics issues in consideration, then those experts with a liberal arts background are likely to offer more professional guidance as to the issues as those with an academic rooting in engineering or science disciplines.

It is striking that even organisations that ostensibly strive to answer questions of ethics on behalf of the technology industry, society, or humanity as a whole often fall into the trap that experts on the subject of Al ethics can only come from the field of Al research. The Future of Life Institute as conceived by Max Tegmark ${ }^{36}$ is as such a notable example.

In contrast to an exclusive approach, a firm might seek to broaden the base of dialogue across the organisation. In

${ }^{35} \mathrm{http}: / /$ www.mondaq.com/uk/x/773622/new+technology/The+role+of+the+Centre+for+Data+Ethi cs+and+Innovation+what+it+means+for+the+UK

${ }^{36}$ Life 3.0, Max Tegmark (2017) 
recognition of the effective management of ethics as being to promote conversation between constituents, inclusive approaches tend to seek to either distribute expertise widely throughout the organisation or seek methods where ethics is derived as a ground-up activity from constituents' backgrounds and cultural references in order to settle upon a set of principles which best reflect that of the firm.

Whereas exclusive approaches suffer from the accusation of tending to technocracy, inclusive methods can be attacked for the tendency to lack rigour in their consideration of the issues at stake. As such, particularly close regard must be made to avoid instances where the voice of ethics in an organisation begins to overlap with a constituency of interests. To that the extent it increases the instance and magnitude of bias and therefore becomes a counterproductive activity. These risks can be mitigated through close attention to principles of diversity of representation, not simply from academic discipline but from as wide variety of cultural backgrounds and from other protected categories so as to as best as possible reflect the diversity of the market in which the organisation operates.

\section{Strategic Integration}

The second axis of tension in competing philosophical bases for ethics is the degree to which ethics is integrated with the strategy of the organisation. While this might appear as synonymous with the previous section's discussion on the need to balance long-term thinking against short-term outcomes, it is not intended as such. Organisations that tend to weigh more heavily short-term goals can be thought of as pursuing 'weak' ethics to the extent they do at all, as opposed to the reference standard that we envisage of a 'strong' ethics management approach. As such, a low level of strategic integration might be perfectly valid for an organisation to develop and will likely score highly against the reference standard that follows assuming it has considered and enacted the various mitigants of the risks of this approach.

The most obvious risk of a low level of strategic integration of ethics is that the topic is simply seen as being 'outsourced' either as a side-of-desk activity or as a tickboxing exercise to a panel of experts. Firms that choose to have low strategic integration of ethics into the design and implementation of technology ought to take particular care of the optics of this approach, and ensure that even while the expertise is disconnected from the activity or the organisation, the communication of ethics matters and the firm's participation in them is maintained in order to stave off potential criticism. That is not to say that high levels of strategic integration don't also come with their risks. There are several obvious risks. The firm focuses so heavily on the potential harms of technology it either chooses to disinvest from innovation or it creates a talking shop culture that equally serves to frustrate any attempt to achieve actual technological progress. Firms that choose to integrate ethics highly within their strategy tend to be those which already have very strong corporate cultures and ones which have already achieved mastery of their sector of expertise. Cynics can argue that ethics are the luxury of the successful, and such cynicism is not unfounded. Google, by way of example, chose to incorporate feedback from users of its successful Gmail platform who were concerned about their scanning of messages in order to help advertisers target commercial messages. It only did so however some thirteen years after launch and only after it had achieved such significant market share that its dominance was ensured.

With the description of these tensions complete, we now make the following definitions of the various methods of managing Digital Ethics in the enterprise:

\section{Ethics Board}

Ethics Boards are created by organisations that favour an expert dominated approach and wish to outsource the handling of ethics concerns to a group that is disconnected to the operational matters involved in the design or implementation of technology.

This is not to say that operational independence isn't desirable from a governance perspective, indeed the reference standard would be an organisation that has achieved a high level of integration between Digital Ethics matters and their existing Governance structures. What separates an Ethics Board however from other methods of managing Digital Ethics is that it is operationally independent in the formation and dissemination of ethics principles. The ethics principles that such firms tend to adopt tend to be driven top-down and are more likely to be reflective of industry concerns as opposed to serving to distinguish the individual characteristics of that which makes the organisation unique.

\section{Ethics Council}

Ethics Councils are developed by organisations who seek to ensure a feedback loop is created within the organisation between the design and implementation of technology and the concerns around the application of it. Like Ethics Boards, they tend to be drawn from external expertise, but they are likely to comprise members with greater industry knowledge as the issues they are likely to devote their time to tend to bear much closer resemblance to the activity of the organisation.

Ethics Councils tend to have strong involvement in the gating of innovation initiatives. It would not be uncommon for projects to require review from the Ethics Council before receiving funding to move to the next step of development. Indeed, the reference standard would involve the Ethics Council in continuous polling of the ethics impact of the host organisation's products and services through research as often is seen in the charity sector. 


\section{Ethics Champions}

Ethics Champions are encouraged by organisations that seek to align the discovery of ethics principles with grassroots interest groups and activism within the firm. A common method of launching such a scheme would be seeking volunteers within the firm or contracting in external experts embedded within technology or innovation teams and championing their presence as being the go-to contacts for discussing the application of technology within the firm.

Firms that choose the home-grown method of building a base of Ethics Champions run the risk of failing to ensure a sufficient diversity of background and viewpoint is included in the ethics conversation. Firms taking this approach can often be accused of letting 'political correctness go mad', as is the case where a little knowledge widely distributed isn't balanced with expertise. Equally, firms that choose to contract in expertise need to caution against having 'ticked' the 'ethics box' without actually achieving the cultural change intended. This can often be spotted by instances of reactive engagement in ethics 'blow-ups' as opposed to proactive considered reasoning of potential issues before they strike.

\section{Ethics Network}

The Ethics Network model is one where ethics is highly distributed through business units as with the Champion approach but is done so with the addition of formal structures much like the operational controls that are seen from Ethics Councils. Such approaches would likely include a degree of expert involvement, as well as naturally seekout industry participation. They would at the same time devote time to considering hypothetical scenarios that would serve to become guardrails for practitioners in the firm to follow.

The Ethics Network model is directly analogous to the postGlobal Financial Crisis management of regulatory compliance. Whereas a 'them and us' culture persisted precrisis between the competing forces for short-term commercial necessity and ensuring long-term stability, post-crisis there is a strong culture of risk-management throughout financial services firms supported by business partners in a central regulatory compliance function. It is likely that firms who adopt this approach might do so in reaction to external pressure as opposed to naturally settling on it as the desired model to balance innovation against long-term goals. And yet it is to be hoped that forward looking firms might adopt a smart network approach to ethics strategy as it is likely to be the most information rich and self-sustaining approach. Time will tell whether sufficient case-studies will serve as models for other organisations to adopt. It is recognised however at time of writing that few examples of this approach can be pointed to.

\section{SECTION VI: MATURITY ASSESSMENT}

With an understanding of a theory of ethics and a conception of the various models to manage the subject and organise a group tasked with its evolution, attention can now be turned to defining the reference standard which organisations can use to both assess their own maturity as well as offer a roadmap for a target state to achieve.

Particular emphasis ought to be placed once again on the intentional lack of value judgments wherever possible in the creation of a maturation assessment, for the appropriate management of ethics within an organisation ought be one free from external judgments which tend to shift over time and according to cultural context. What is offered instead are some structural principles that serve to help organisations to define the balance of values across their constituent groups.

Use of this framework, regardless of which model is used to operationally handle ethics challenges ought to steer an organisation away from whimsy and purely aesthetic judgment. It is unlikely that an organisation that follows this schema to its most developed level would conceive of an application of technology that is particularly abhorrent to any constituent stakeholder group. If that transpires to be the case in practice then we have succeeded in our goal of setting out guiderails for ethical evaluation without prescribing any ethical principles ourselves.

The final point to make in the introduction of these assessment criteria is to encourage the reader to seek methods authentic to their own organisational culture for fulfilling the criteria articulated in the matrix. What is most effective is to follow emergent design principles. Approach the problems at hand with the method that is most likely to solve it while simultaneously moving towards the goal of ethical development. There is a temptation to overengineer a method at the outset of their design journey. In short, we encourage pragmatism over idealism and observe that organisations that are guided by this instinct tend to reach more satisfactory conclusions on their Digital Ethics development than those which seek to anticipate in a vacuum without gaining real-world experience of how to practically implement these measures.

\section{Cultural Reflection}

Cognisance of culture is easy to say, and hard to identify, and a near possibility to achieve fully. Recognition that we are all products of our own natural gifts and weaknesses as well as the cumulative effect of our wealth of experiences and reinforced predilections over our lifetime is perhaps as individuals the only level of transcendence we can realistically hope to achieve. At a macro-level, ensuring that all cultural sensitivities are respected is in practice a bar too high. Certainly it can be expected that at least if an organisation has sought to encourage representation in 
Digital Ethics issues at least with an equivalence of diversity as exists across the markets in which it operates, then it ought to be protected against the likelihood of significant boundary crossings that might stir the level of controversy that leads to lasting reputational harm as well as actual damage.

A mistake that is all too often seen is that a one-size fits all approach is sufficient or desirable. A well-documented example of this in recent years is how Facebook has sought to devise a codex of acceptable content principles that are universal in scope and application across the entire platform ${ }^{37}$. Not only is it seeking to undertake an intractable task, but it is making a secondary mistake in outsourcing this function to a team from a unitary cultural background (in the case of Facebook, their content review team is based in Manila).

Organisations who recognise diversity will be quick to ensure that protected categories (such as race, gender, religious conviction etc) are represented within the Digital Ethics conversation, and as a subsequent step should target at least that level of representation that exists within the cultural footprint of the firm. A Scottish internet start-up that has a Digital Ethics team who are all from Scotland would be highly scored against the reference standard if it only operates in the Scottish market. If, however it was based in Edinburgh but operates across the United Kingdom then unless its Digital Ethics team was rebalanced at most it could expect to achieve a level-four rating out of five (see Figure 4, below).

\section{Design Integration}

The modern method of design recognises that an interdisciplinary approach to design is likely to yield a superior result to one where all the project team share a similar technical background. The modern approach to architectural design is an excellent example of this ${ }^{38}$. While in the past the technical drawings might be reviewed by a civil engineer for feasibility before finally reaching the local town planning department, the modern method seeks to involve stakeholders throughout the development process, even from inception in order to ensure the feasibility and desirability (as well as the commercial success) of the initiative from the outset.

Too often though, it is experienced that engineering teams see their job as being the novel discovery or integration of a technical method without regard to the necessity of potential ethics concerns being addressed: “this isn't my job", or "it's an important task, but I'm just the software developer", or "it's something we haven't got around to thinking about yet", are responses which are all too often heard.
An absolute minimum level of consideration that should be expected of organisations which seek to innovate responsibly would be to ensure that an initiative passes through a Digital Ethics checkpoint at the very least before it is tested on real users. For most innovation teams, this would be the separation between either an evaluation and proof-of-concept stage, or between proof-of-concept and pilot stages.

There remains an inherent risk though with this approach. The ethical evaluation, in being retrospectively applied, doesn't consider sufficient alternative outcomes. An example of this might be in the use of machine learning in credit decisioning processes. A proof-of-concept might demonstrate that a particular algorithmic approach achieves a high level of accuracy. If considered in isolation at the late stage of the initiative then the potential risks around bias might be downplayed or certified as having been mitigated. The same initiative where Digital Ethics is a design consideration at inception however, might have recognised the potential for bias exists in exploring a machine learning method, and might have encouraged the design team to consider alternative approaches such as decision trees where any bias would be more explicitly visible in the design and therefore more easily counteracted. Considering Digital Ethics at the inception of an initiative can go a long way to avoiding such cases of confirmation bias in the design choices being made.

Again, what is important to stress with regards to this example, is that it is not an evaluation of bias that is an ethical discussion. As explained in section III, bias and techniques to overcome it are inherently a matter for risk/ safety management. What is the scope of an ethics discussion however is whether sufficient regard has been given to the potential for bias, or whether a prioritisation of values according to guiding principles is an intentional act as opposed to being capricious in nature?

The various higher levels of attainment according to the criteria of design integration reflect the richness and granularity afforded to the handling of ethics throughout the full lifecycle of any technical initiative. It is expected that only truly interdisciplinary diverse teams are likely to score highly according to this measure.

\section{Dialogue Sophistication}

To achieve a high level of sophistication around their Digital Ethics dialogue it is not necessary for a firm to solicit the participation of experts in the process. Sophistication correlates more with diverse inclusion.

In order to achieve a high level of intellectual rigour around the discussion, then external expertise will be inevitable, but even firms which choose a high level of inclusive Digital Ethics management with the cultivation of grass-roots

\footnotetext{
${ }^{37}$ https://www.wnycstudios.org/podcasts/radiolab/articles/post-no-evil
} 
initiatives will find need to resort to bringing expertise onboard to ensure confidence can be maintained in the quality of its thought and discussion.

While these criteria undoubtedly place a value on the inclusion of expertise, it will be clear to most readers that simply the involvement of experts in the Digital Ethics conversation does not necessarily achieve a high score. The lower scores are separated by the move from arbitrariness to rules, and then to rules or principles that at least have their rationale explained. There are many examples of firms which have taken a stance on particular issues but without any regard to explaining the various considerations that were made in reaching that determination ${ }^{39}$.

It is also expected that firms that document the rationale for their approaches will be able to articulate it in sufficient detail to remove ambiguity. A common example is a helpful "?" icon next to a data entry field with an explanation of why that data is being collected. An explanation of "we collect your date of birth in order to provide a better userexperience" would fall short of our test. Firstly, it is not at all clear how the collection of this data achieves the result of improving user-experience. Secondly, there is too much ambiguity as to whether this is genuinely the reason stated. A better example is, "we ask you provide your year of birth as this is a simple way of grouping you along with other users so we can better reflect design or features that might appeal to you and those of a similar age. Most of our services can be used without you being required to provide your actual day and month of birth, but where this is required, we do so in order to identify you and comply with relevant legislation [specified]". It is easy to see how many of the online services we take for granted would score very low according to these criteria.

It is outside of the scope of this paper, but we do see a clear opportunity for a regulator or standards setting agency to step in specifically in relation to terms and conditions for digital services and seek to harmonise language and consequences much as allergen information is increasingly being simplified and transparently presented to customers.

We see the reference standard according to these criteria to be an organisation that seeks to promote public debate on the subject of Digital Ethics and has this incubator report on activity to its Board and executive leadership team.

\section{Internal Access}

A concern of many teams who are tasked with general professional conduct is that the burden of managing Digital Ethics at scale will likely fall on them. Some choose to deflect this responsibility, while others consider what is the minimum action necessary to invite concerns but without any formal review process by which those concerns can be tested.

We separate a formal whistle-blower mechanism from an open reporting system. We expect a whistle-blower mechanism will add formality of process and auditability of response to what otherwise is simply a crowdsourcing of concerns. Teams tasked with Digital Ethics undoubtedly will discover that issues raised will vary from the real to the random and will need to devise a method to filter noise without discouraging the worried to come forward. Some level of open forum convened on a regular basis to raise awareness of the subject, to test concerns, and publicise principles will be required to achieve an upper median score.

What is expected of firms to score highly according to this criterion is to provide an additional escalation point externally to the operational process. This might be similar in character to how complaints handling processes are expected in the Financial Services industry. The highest standard draws inspiration from how the best academic and medical institutions consider breaches of ethics and have built review processes to ensure the external accreditation of their methods in order to achieve a high level of public confidence in their approach ${ }^{40}$.

\section{Method Awareness}

The most basic weakness we see in organisations who say they are taking the question of Digital Ethics seriously is that the way the organisation understands and articulates the various domains of ethics is confused. While some organisations might be advanced in providing 'ethics' training to technical audiences, they would still score low on this scale if they haven't separated the domains of risk/ safety management from regulatory concerns and encouraged their teams to think along these lines.

Subsequent levels are reached by the level of education offered, with an expectation that the organisations who treat this area the most seriously will mandate basic training on the subject to all employees much in the same way as it might offer training on the company's other policies and procedures on a regular basis.

It is expected that various regulators will intervene to ensure that firms provide Digital Ethics training to employees, and so it is hoped that these scoring criteria will necessarily adapt as this field matures.

The reference standard is clear accountability of Digital Ethics in the equivalent manner as other issues such as anti-bribery and corruption would be managed.

\footnotetext{
${ }^{39} \mathrm{https}: / /$ www.independent.co.uk/life-style/gadgets-and-tech/news/google-dont-be-evil-codeconduct-removed-alphabet-a $8361276 . \mathrm{html}$
} 


\section{Stakeholder Participation}

There are two initial points to note on the subject of stakeholder participation. Firstly, a median score can be achieved simply by encouraging wide participation within an organisation. This ought to be simple for all organisations to achieve and the benefits such that it should be rewarded commensurately. Secondly, that these criteria differ from that of cultural reflection as stakeholder participation is concerned with the extent to which there are touchpoints across functional groups across the organisation as opposed to any qualitative perspective that participants bring. Organisations that achieve the highest levels should be particularly commended as they have achieved the additionally brave and complex steps of engaging externally on the subject. Already we see organisations such as Microsoft and IBM speaking with customers about their Digital Ethics efforts, which is to be encouraged, but unless these organisations have already achieved a sufficiently strong footprint for Digital Ethics handling internally then they will still score low on this scale. It is also worth noting that merely talking with customers isn't sufficient, actual engagement with customers is what is required. Ethics is a bilateral activity not merely a marketing opportunity.

\section{Substantive Transparency}

Again, these criteria might seem to resemble one that has come before it, but it differs. The test of rigour in dialogue sophistication is looking at how well reasoned a principle is, the test for transparency is concerned with the efforts by which that reasoning is communicated. There are already examples of firms who have appointed Ethics Boards to construct a set of principles by which technology teams need adhere, but without taking the additional step of ensuring that the composition of such Boards and their work is well communicated ${ }^{41}$.

\begin{tabular}{|c|c|c|c|c|c|c|}
\hline & & $\star$ & $\star$ & $\star \star \star \star ~$ & 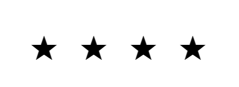 & 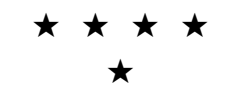 \\
\hline $\begin{array}{l}\text { Cultural } \\
\text { Reflection }\end{array}$ & $\begin{array}{l}\text { No recognition of } \\
\text { cultural distinction } \\
\text { of Digital Ethics } \\
\text { matters. }\end{array}$ & $\begin{array}{l}\text { One size fits all } \\
\text { approach. }\end{array}$ & $\begin{array}{l}\text { Interdisciplinary } \\
\text { viewpoint diversity } \\
\text { within the } \\
\text { development } \\
\text { team. }\end{array}$ & $\begin{array}{l}\text { Protected category } \\
\text { diversity within the } \\
\text { development } \\
\text { team. }\end{array}$ & $\begin{array}{l}\text { Engagement } \\
\text { representative of } \\
\text { cultural footprint } \\
\text { of firm. }\end{array}$ & $\begin{array}{l}\text { Engagement } \\
\text { representative of } \\
\text { the market the } \\
\text { firm operates in. }\end{array}$ \\
\hline $\begin{array}{l}\text { Design } \\
\text { Integration }\end{array}$ & $\begin{array}{l}\text { Digital Ethics not a } \\
\text { design or } \\
\text { engineering team } \\
\text { consideration. }\end{array}$ & $\begin{array}{l}\text { Digital Ethics } \\
\text { checkpoint at } \\
\text { design completion. }\end{array}$ & $\begin{array}{l}\text { Digital Ethics } \\
\text { checkpoint at } \\
\text { inception of } \\
\text { initiative. }\end{array}$ & $\begin{array}{l}\text { Digital Ethics } \\
\text { checkpoints } \\
\text { throughout } \\
\text { iteration/ design } \\
\text { stages. }\end{array}$ & $\begin{array}{l}\text { Customer Focus } \\
\text { Groups. }\end{array}$ & $\begin{array}{l}\text { Post-Release } \\
\text { Follow up. }\end{array}$ \\
\hline $\begin{array}{l}\text { Dialogue } \\
\text { Sophistication }\end{array}$ & $\begin{array}{l}\text { Arbitrary } \\
\text { adjudication of } \\
\text { Digital Ethics } \\
\text { Challenges without } \\
\text { rationale. }\end{array}$ & $\begin{array}{l}\text { Rules based } \\
\text { approach. }\end{array}$ & $\begin{array}{l}\text { Review process for } \\
\text { consistency with } \\
\text { documented } \\
\text { rationale. }\end{array}$ & $\begin{array}{l}\text { External expertise } \\
\text { in the } \\
\text { development and } \\
\text { assessment of } \\
\text { Digital Ethics } \\
\text { principles. }\end{array}$ & $\begin{array}{l}\text { Interdisciplinary } \\
\text { advisory board of } \\
\text { academics with } \\
\text { transparency of } \\
\text { representation. }\end{array}$ & $\begin{array}{l}\text { Ethics incubator } \\
\text { that convenes } \\
\text { publicly and } \\
\text { reports out to } \\
\text { Board and Senior } \\
\text { Executives. }\end{array}$ \\
\hline $\begin{array}{l}\text { Internal } \\
\text { Access }\end{array}$ & $\begin{array}{l}\text { No distinct issue } \\
\text { reporting pathway } \\
\text { for Digital Ethics } \\
\text { concerns. }\end{array}$ & $\begin{array}{l}\text { Suggestion box or } \\
\text { other anonymous } \\
\text { issue reporting } \\
\text { system. }\end{array}$ & $\begin{array}{l}\text { Whistle-blower } \\
\text { Mechanism. }\end{array}$ & Open Forum. & $\begin{array}{l}\text { Provision of } \\
\text { Internal } \\
\text { Ombudsman } \\
\text { Service. }\end{array}$ & $\begin{array}{l}\text { Commitment to } \\
\text { Visiting Committee } \\
\text { Review and } \\
\text { Accreditation. }\end{array}$ \\
\hline $\begin{array}{l}\text { Method } \\
\text { Awareness }\end{array}$ & $\begin{array}{l}\text { Ad-hoc } \\
\text { understanding of } \\
\text { Digital Ethics } \\
\text { within the } \\
\text { organisation. }\end{array}$ & $\begin{array}{l}\text { Organisational } \\
\text { articulation of the } \\
\text { separation between } \\
\text { Regulatory } \\
\text { Compliance, Risk/ } \\
\text { Safety, and Digital } \\
\text { Ethics. }\end{array}$ & $\begin{array}{l}\text { The dissemination } \\
\text { of effective } \\
\text { explanatory } \\
\text { materials. }\end{array}$ & $\begin{array}{l}\text { The addition of } \\
\text { optional } \\
\text { Professional } \\
\text { Development } \\
\text { training to } \\
\text { interested parties. }\end{array}$ & $\begin{array}{l}\text { Mandatory } \\
\text { Continuous } \\
\text { Professional } \\
\text { Development with } \\
\text { Worked case-study } \\
\text { examples. }\end{array}$ & $\begin{array}{l}\text { Accountability of } \\
\text { Digital Ethics } \\
\text { within Governance } \\
\text { Structure. }\end{array}$ \\
\hline $\begin{array}{l}\text { Stakeholder } \\
\text { Participation }\end{array}$ & $\begin{array}{l}\text { Ad-hoc } \\
\text { participation in } \\
\text { Digital Ethics } \\
\text { debate. }\end{array}$ & $\begin{array}{l}\text { Participation from } \\
\text { interested } \\
\text { individuals only. }\end{array}$ & $\begin{array}{l}\text { Participation from } \\
\text { those involved in } \\
\text { the design and } \\
\text { delivery of } \\
\text { technology. }\end{array}$ & $\begin{array}{l}\text { Firmwide } \\
\text { participation. }\end{array}$ & $\begin{array}{l}\text { Engagement with } \\
\text { Business Partners } \\
\text { and Stakeholders. }\end{array}$ & $\begin{array}{l}\text { Engagement with } \\
\text { customers and the } \\
\text { wider public. }\end{array}$ \\
\hline $\begin{array}{l}\text { Substantive } \\
\text { Transparency }\end{array}$ & $\begin{array}{l}\text { No distinct Digital } \\
\text { Ethics principles. }\end{array}$ & $\begin{array}{l}\text { Explicit Digital } \\
\text { Ethics principles. }\end{array}$ & $\begin{array}{l}\text { Internal } \\
\text { Dissemination of } \\
\text { Digital Ethics } \\
\text { principles. }\end{array}$ & $\begin{array}{l}\text { Explanation of } \\
\text { rationale for Digital } \\
\text { Ethics principles. }\end{array}$ & $\begin{array}{l}\text { Regular Internal } \\
\text { Survey of } \\
\text { continued } \\
\text { relevance and } \\
\text { application of } \\
\text { principles. }\end{array}$ & $\begin{array}{l}\text { Holding firm to } \\
\text { account publicly on } \\
\text { Digital Ethics } \\
\text { principles. }\end{array}$ \\
\hline
\end{tabular}

Figure 4: Assessing Digital Ethics maturity can offer organisations a roadmap towards the reference standard.

\footnotetext{
${ }^{41}$ https://www.vox.com/future-perfect/2019/4/4/18295933/google-cancels-ai-ethics-board
} 


\section{CONCLUSION}

This new knowledge arms us. We are better equipped to manage initiatives in such a way as to consistently achieve outcomes that protect us, our colleagues, institutions, and the wider society.

It will also be clearer to us where we are exposed. This will be either because we haven't developed a sufficiently rich articulation for what Digital Ethics is, or we haven't recognised the imperative for progress towards the reference standard. As explained, organisations tend to be most at risk when they purport to speak about Digital Ethics issues, but only centre on matters concerning risk or safety management. This leaves them blindsided when a backlash occurs. Worse, it can leave organisations in a state of deluded denial of the risks they are exposed to. If you began this paper unconvinced on this point, we hope you are left feeling a renewed sense of urgency to take action on these matters.

The very basic level or understanding that we hope this paper sets out the case for is to insist on the separation of the domain of ethics management from that of regulatory compliance and risk/ safety management. Without this foundation in place, conversations on the subject can very easily meander across various conceptual boundaries, and while might make for interesting soundbites, seldom result in conclusive outcome.

Each organization will need to decide on the most appropriate model to develop in handling Digital Ethics as a subject. Here we offer no judgement, only a recognition that there are pros and cons to each option, but what is important is that at least some introspection is made as to what the most appropriate starting point might be - and allowing flexibility for this to develop over time should it no longer serve the long-term strategic interests for the firm.

Finally, thought will be given to how to mature the management of Digital Ethics in such a way as to best adopt and adapt the reference standard. Such organizations will lead the way in terms of application of technology so as to be a beacon to others in the industry or market in which your organisation operates.

Those in the investment community might want to consider using this approach in order to make assessments on investment criteria. There is certainly an opportunity currently to offer investors a basis to invest according to a marketplace of principles. If the current ESG movement develops along a continued trajectory, it won't be long before questions of Digital Ethics governance are spoken of alongside those of environmental sustainability or modern slavery.
Most importantly however, we hope that the reader is left with a greater understanding of the conceptual framework in which an articulation of ethics operates. Too much work on this subject is centred merely on the rights and wrongs of various approaches or taking a vitriolic stance on other important issues such as ensuring that our technology doesn't automate away the things which are most important in life or exacerbate unintentionally the various inequalities of our modern world. These issues are of critical concern, but it is of equal danger to see them as the sole extent of ethics matters, or to attempt to manage them all in the same manner.

To be sure, the management of Digital Ethics needs to live in balance with other competing interests, and a firm that is oblivious to technical or regulatory risks will be unlikely to endure in the medium or long term. While Digital Ethics is very much though a question of consideration of issues that have an impact across longer time horizons, it simply ought not be ignored - lessons from history surely teach us this if nothing else.

The imperative for taking this approach is that we avoid creating the conditions that will lead to inevitable backlash. We have seen this occurring in other domains such as Financial Services organisations in the aftermath of the global financial crises and the heightened environmental activism that we are currently experiencing. This is of course leaving aside the more acute examples of techlash such as that exemplified by Ted Kaczynski.

The overarching theme of this paper is to stress that Digital Ethics management is about instigating and cultivating effective conversations at scale. We are blessed with the capacity for language, but too many of the conversations we engage in are one-sided - argumentative in construction and aimed at getting our point across rather than hearing what the other side says or feels.

What we need to develop are conversational forms that sufficiently capture the 'data' of real experience and engage the ethical problems implicit in that data. We need to speak and listen to each other differently than we have heretofore. Modes of conversation geared to winning are not the most effective or inclusive ways to solve problems, especially ethical ones with such widespread impact.

Perhaps this is the greatest guidance anyone can offer on the subject, if an organisation does nothing else but creates opportunities to listen - then it would have achieved more than many that have come before it. For in listening to our colleagues, customers, and those who represent constituent members of wider society, we stand the greatest chance to learn what is valuable to them - and this, at its core is exactly what ethics is about. 


\section{BIBLIOGRAPHY}

Nichomachean Ethics, Aristotle

Groundwork for the Metaphysics of Morals, Immanuel Kant (1785)

Critique of Practical Reason, Immanuel Kant (1788)

The Moral Philosopher and the Moral Life, William James, International Journal of Ethics, volume 1, number 3 (April 1891)

A Pluralistic Universe, William James (1909)

Lecture on Ethics, Ludwig Wittgenstein (1929)

Philosophical Investigations, Ludwig Wittgenstein (1953)

Ich and Du, Martin Buber (1923)

Politics as Vocation, Max Weber (1919)

Negative Dialectics, Theodore Adorno (1966)

Communication and the Evolution of Society, Jurgen Habernas (1976)

Consciousness and the Acquisition of Language, Maurice Merleau-Ponty (1949)

The Infinite Conversation, Maurice Blanchot (1969)

An Examination of the Place of Reason in Ethics, Stephen Toulmin (1986)

Philosophy of Technology, Don Ihde (1998)

Bodies in Technology, Don Ihde (2001)

Digital Media: Human- Technology Connection, Don Ihde (2016)

The Ontological Dimension of Embodiment: Heidegger's Thinking of Being, David Kleinberg-Levin (1999)

Modernity and the Hegemony of Vision, David Michael Levin (1993)

After Virtue: A Study in Moral Theory, Alasdair Maclntyre (2007)

What is Intersubjectivity? John J McGraw (2012)

Types of Intersubjectivity and Alternative Reality Images, Ulrich de Balbian (2017)

Modernity and morality in Habermas' discourse ethics, James Gordon Finlayson (2000)

Understanding Digital Ethics: Cases and Contexts, Jonathan Beever, Rudy McDaniel and Nancy Stanlick (2019)

Three Things Digital Ethics can Learn From Medical Ethics, Carissa Veliz (2019)

Translating Principles into Practices of Digital Ethics: Five Risks of Being Unethical, Luciano Floridi (2019)

Engineering, Digital Societies and Infosphere. An Interpretation of Luciano Floridi's Philosophy and Ethics of Information, Lola Almendros (2019)

What Does an Al Ethicist Do? Thomas Davenport (2019)

The Ethics of Artificial Intelligence, Nick Bostrom \&Eliezer Yudkowsky (2011)

The Age of Surveillance Capitalism, Shoshana Zuboff (2019)

The Interpersonal Theory of Psychiatry, Harry Stack Sullivan (1953)

Playing and Reality, D W Winnicott (1971)

Human Nature, D W Winnicott (1988)

Psychoanalytic Studies of Personality, W R D Fairbairn (1952)

Countertransference, Harold Searles (1996)

Object Relations and the Developing Ego, Althea Horner (1995)

Collected Papers, Milton Erickson (1980)

The Social Construction of Reality, Peter Berger \& Thomas Luckman (1991)

From Psyche to System, Carl Whitaker (1982)

Family Therapy in Clinical Practice, Murray Bowen (1978)

Beyond Doer and Done To, Jessica Benjamin (2017)

Countertransference, Lawrence Epstein \& Arthur Feiner (1977)

Thinking in Systems, Donatella Meadows (2017)

Complexity and the Nexus of Leadership, Jeff Goldstein et al (2010)

Industrial Dynamics, Jay W Forrester (2013)

Observing Interaction: An Introduction to Sequential Analysis, Roger Bakeman \& John Gottman (1997)

You are the Product, John Lanchester (2017)

Constructionism, Seymour Papert \& Irit Harel (1991)

The Children's Machine: rethinking school in the age of the computer, Seymour Papert (1993)

Robot Rules: Regulating Artificial Intelligence, Jacob Turner (2018) 


\section{ABOUT THE AUTHORS}

\section{Charles Radclyffe}

Charles holds an MA in Law from the University of Cambridge but has spent his career in the technology industry. He has built and sold three technology companies and failed at a fourth - which he maintains to be a much more interesting story.

In between each of his entrepreneurial endeavours, he has been a sought-after expert consulting to Financial Services organisations on how best to implement emerging technology and develop innovation strategy. Most recently, he was the Head of Technology for Deutsche Bank's Innovation Labs in London, and subsequently has driven the strategy for Al at Fidelity International. He is a Visiting Fellow at the University of Bristol.

Charles is a Forbes contributor and has presented around the world on subjects relating to the field of technology and societal change, including two TEDx talks which are available online.

\section{Richard Nodell}

Dick's relationship to the field of Al began witnessing and participating in the early discussions where Marvin Minsky and Seymour Papert argued for what is now called AGI as opposed by Hubert Dreyfus at MIT in the 1960's. In a career that spans over four decades, Dick has specialised in working with leaders of large complex organisations. Originally Dick founded and led a company that consulted to the for-profit sector, primarily in the technology and Wall Street financial industries: Bell Telephone Laboratories, GE, Goldman Sachs, American Express, IBM, and AT\&T. His work later shifted towards mission-driven organisations and over the last 25 years he has worked with leaders in higher education, public media and research science.

What distinguished Dick's work is a multi-dimensional approach to leadership that includes understanding organisations as nonlinear dynamical systems, effective practices and design thinking. Believing that no one theory or template will apply, he helps leaders and individuals develop their own distinctive modes of leading themselves and others.

In addition to his consulting and executive coaching practice, Dick recently retired from a long career practicing psychotherapy in New York City. 